Portland State University

PDXScholar

Civil and Environmental Engineering Faculty

Publications and Presentations

Civil and Environmental Engineering

9-2015

\title{
Development of a Pedestrian Demand Estimation Tool
}

Kelly Clifton

Portland State University, kclifton@pdx.edu

Patrick Allen Singleton

Portland State University, singletonpa@gmail.com

Christopher D. Muhs

Portland State University, cdmuhs@gmail.com

Robert J. Schneider

University of Wisconsin - Milwaukee

Follow this and additional works at: https://pdxscholar.library.pdx.edu/cengin_fac

Part of the Civil Engineering Commons, Environmental Engineering Commons, Transportation Engineering Commons, and the Urban Studies Commons

Let us know how access to this document benefits you.

\section{Citation Details}

Clifton, K., Singleton, P., Muhs, C., and Schneider, P. (2015). Development of a Pedestrian Demand Estimation Tool. Report NITC-RR-677. Portland, OR: Transportation Research and Education Center (TREC), 2015. http://dx.doi.org/10.15760/trec.124

This Report is brought to you for free and open access. It has been accepted for inclusion in Civil and Environmental Engineering Faculty Publications and Presentations by an authorized administrator of PDXScholar. Please contact us if we can make this document more accessible: pdxscholar@pdx.edu. 


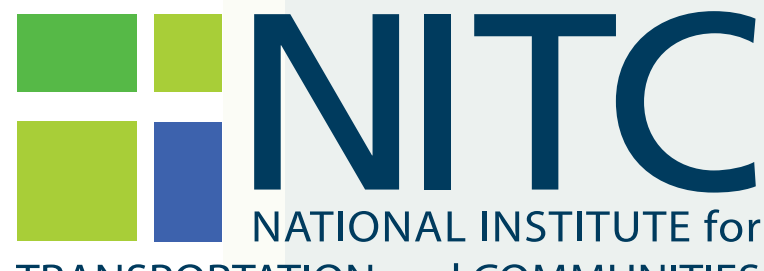

TRANSPORTATION and COMMUNITIES

FINAL REPORT

Development of a Pedestrian Demand Estimation Tool

NITC-RR-677 September 2015

NITC is the U.S. Department of Transportation's national university transportation center for livable communities.

\#": TREC 


\title{
DEVELOPMENT OF A PEDESTRIAN DEMAND ESTIMATION TOOL
}

\author{
Final Report \\ NITC-RR-677 \\ by \\ Kelly J. Clifton, $\mathrm{PhD}^{1}(\mathrm{PI})$ \\ Patrick A. Singleton ${ }^{1}$ \\ Christopher D. Muhs ${ }^{1}$ \\ Robert J. Schneider, $\mathrm{PhD}^{2}$ \\ ${ }^{1}$ Portland State University \\ ${ }^{2}$ University of Wisconsin-Milwaukee \\ for \\ National Institute for Transportation and Communities (NITC) \\ P.O. Box 751 \\ Portland, OR 97207
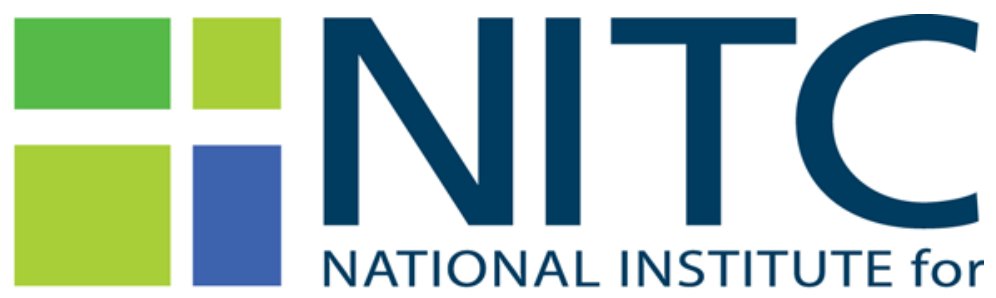 \\ TRANSPORTATION and COMMUNITIES
}

September 2015 



\section{Technical Report Documentation Page}

\begin{tabular}{|l|l|l}
\hline $\begin{array}{l}\text { 1. Report No. } \\
\text { NITC-RR-677 }\end{array}$ & 2. Government Accession No. & \\
\hline 4. Title and Subtitle & & \\
\hline
\end{tabular}

4. Title and Subtitle

Development of a Pedestrian Demand Estimation Tool

5. Report Date

September 2015

6. Performing Organization Code

7. Author(s)

8. Performing Organization Report No.

Kelly J. Clifton; Patrick A. Singleton; Christopher D. Muhs; Robert J. Schneider

9. Performing Organization Name and Address

10. Work Unit No. (TRAIS)

Portland State University, Department of Civil \& Environmental Engineering

PO Box 751 - CEE

Portland, OR 97207-0751

11. Contract or Grant No.

12. Sponsoring Agency Name and Address

13. Type of Report and Period Covered

National Institute for Transportation and Communities (NITC)

P.O. Box 751

Portland, Oregon 97207

14. Sponsoring Agency Code

15. Supplementary Notes

16. Abstract

Most research on walking behavior has focused on mode choice or walk-trip frequency. In contrast, this study is one of the first to analyze the destination choice behaviors of pedestrians. Using about 4,500 walk trips from a 2011 household travel survey in the Portland, OR, region, we estimated multinomial logit pedestrian destination choice models for six trip purposes. Independent variables included terms for impedance (walk-trip distance); size (employment by type, households); supportive pedestrian environments (parks, a pedestrian index of the environment variable called PIE); barriers to walking (terrain, industrial-type employment); and traveler characteristics. Unique to this study was the use of small-scale destination zone alternatives.

Distance was a significant deterrent to pedestrian destination choice, and people in carless or childless households were less sensitive to distance for some purposes. Employment (especially retail) was a strong attractor: doubling the number of jobs nearly doubled the odds of choosing a destination for home-based shopping walk trips. More attractive pedestrian environments were also positively associated with pedestrian destination choice after controlling for other factors. These results shed light on determinants of pedestrian destination choice behavior, and sensitivities in the models highlight potential policy-levers to increase walking activity. In addition, the destination choice models can be used in regional travel demand models or as pedestrian planning tools to evaluate land use and transportation policy and investment scenarios.

\section{Key Words}

walking; pedestrians; destination choice; travel behavior; built environment; active transportation

\section{Distribution Statement}

No restrictions. Copies available from NITC: www.nitc.us

\begin{tabular}{|l|l|l|c|}
\hline $\begin{array}{l}\text { 19. Security Classification (of this report) } \\
\text { Unclassified }\end{array}$ & $\begin{array}{c}\text { 20. Security Classification (of this page) } \\
\text { Unclassified }\end{array}$ & $\begin{array}{c}\text { 21. No. of Pages } \\
33\end{array}$ & 22. Price \\
\hline
\end{tabular}




\section{ACKNOWLEDGEMENTS}

This project was funded by the National Institute for Transportation and Communities (NITC) and Metro, the regional government for the Portland, OR, metropolitan area. The authors thank colleagues from Metro, Portland State University and the University of Wisconsin, Milwaukee, for their insights and interest in this topic.

\section{DISCLAIMER}

The contents of this report reflect the views of the authors, who are solely responsible for the facts and the accuracy of the material and information presented herein. This document is disseminated under the sponsorship of the U.S. Department of Transportation University Transportation Centers Program and Portland State University in the interest of information exchange. The U.S. Government and Portland State University assumes no liability for the contents or use thereof. The contents do not necessarily reflect the official views of the U.S. Government and Portland State University. This report does not constitute a standard, specification, or regulation. 


\section{TABLE OF CONTENTS}

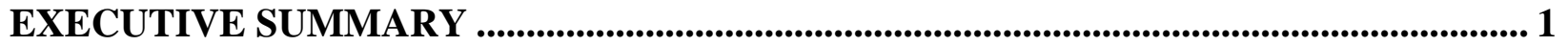

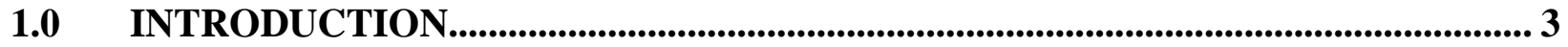

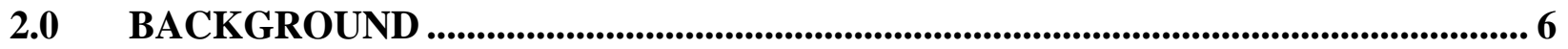

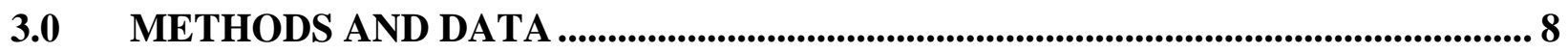

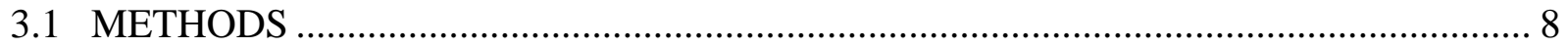

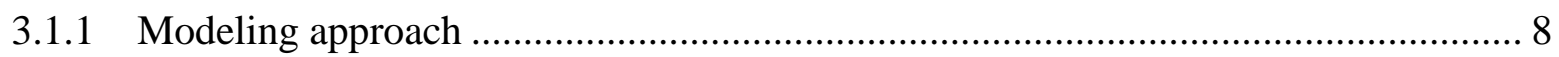

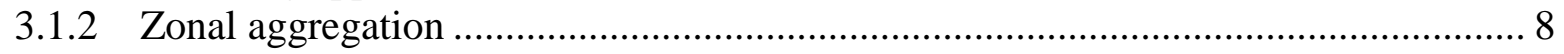

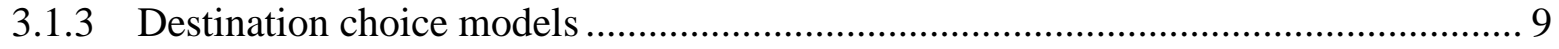

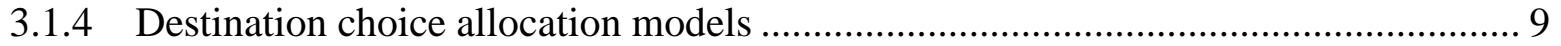

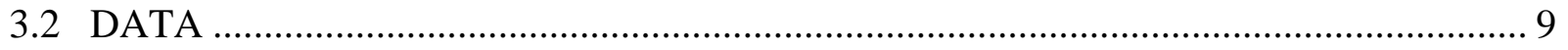

3.2.1 Pedestrian travel behavior.......................................................................... 9

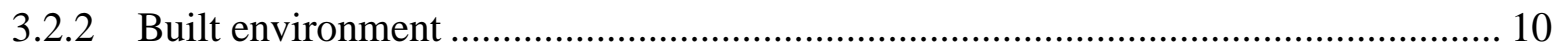

4.0 MODELING RESULTS......................................................................................... 12

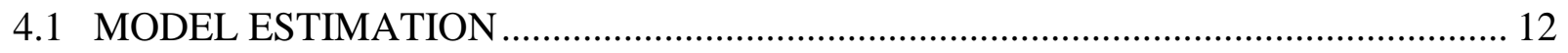

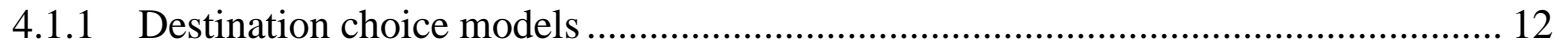

4.1.2 Destination choice allocation models ............................................................... 15

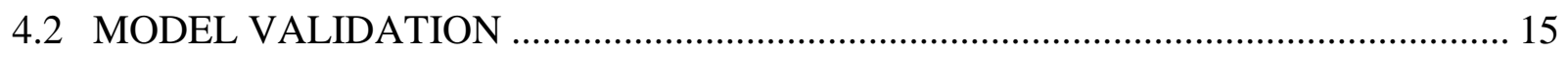

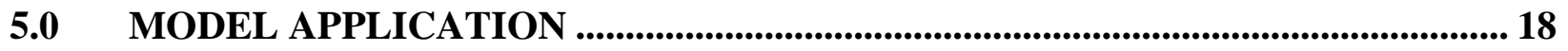

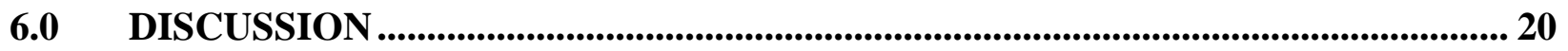

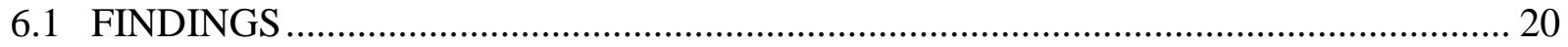

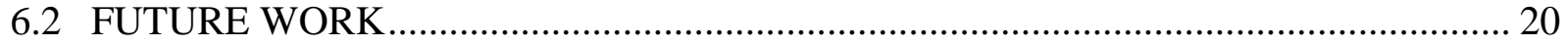

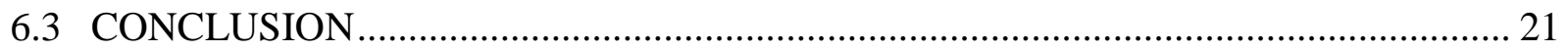

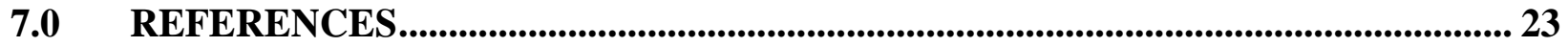




\section{LIST OF TABLES}

Table 3.1 Descriptive statistics for pedestrian destination choice model variables.................... 11

Table 4.1 Results of pedestrian destination choice models 12

\section{LIST OF FIGURES}

Figure 1.1 Framework to increase representation of walking in conventional travel demand models (from Clifton et al., 2013) .......................................................................... 4

Figure 3.1 Framework for pedestrian destination choice...................................................... 8

Figure 4.1 Relative sensitivities of pedestrian destination choice attributes .............................. 15

Figure 4.2 Percentage of trips where modeled destination was correct, by trip purpose ............. 16

Figure 4.3 Modeled probability of selecting the correct destination, mean, by trip purpose ....... 16 Figure 4.4 Walk-trip length (miles) for modeled and correct destinations, mean, by trip purpose

Figure 5.1 Predicted HBO walk-trip productions for a subset of Portland-area PAZs................ 18

Figure 5.2 Predicted proportion of HBO walk trips from origin to superPAZ destinations......... 19 


\section{EXECUTIVE SUMMARY}

There is growing support to improve the quality of the walking environment and make investments to promote pedestrian travel. Such efforts often require analytical non-motorized planning tools to estimate levels of pedestrian demand that are sensitive to environmental and demographic factors at an appropriate scale. Despite this interest and need, current forecasting tools, particularly regional travel demand models, often fall short. Until recently, spatially disaggregate travel behavior data on walking activity and detailed data on the quality of the pedestrian environment have been generally unavailable.

Recent work by the authors attempts to utilize a new availability of data to develop robust pedestrian planning tools for use in regional travel demand modeling. A project through the Oregon Transportation Research and Education Consortium (OTREC), in partnership with Portland's metropolitan planning organization Metro, developed a pedestrian modeling framework for use in four-step travel demand models. It constructed models to predict the number of walk trips generated with spatial acuity, utilizing a new measure of the pedestrian environment and a micro-level unit of analysis. This National Institute for Transportation and Communities (NITC) project builds off of the successes of the authors' previous work, continues the collaboration with Metro, and extends the pedestrian demand estimation tool's functionality to encompass pedestrian destination choice.

Specifically, this project developed statistical models of pedestrian choice behavior, predicting the distribution of walk trips generated (from the previous project) to destinations also at a small spatial scale. Using about 4,500 walk trips from a 2011 household travel survey in the Portland region - the Oregon Household Activity Survey (OHAS)—multinomial logit pedestrian destination choice models were estimated for six trip purposes. Independent variables included terms for walk-trip distance; employment by type; households; supportive pedestrian environments (parks, a pedestrian index of the environment variable called PIE); barriers to walking (terrain, freeways, industrial-type employment); and traveler characteristics. Destination alternatives were uniform square analysis zones with quarter-mile (400m) sides.

Results suggest important behavioral influences on walking. Distance was a significant deterrent to pedestrian destination choice, and people in carless or childless households were less sensitive to distance for some purposes. Employment (especially retail) was a strong attractor: doubling the number of jobs nearly doubled the odds of choosing a destination for home-based shopping walk trips. More attractive pedestrian environments were also positively associated with pedestrian destination choice after controlling for other factors.

This research makes several important contributions. Notably, it is one of the first studies to explore the destination-choice dimension of pedestrian travel behavior. It addition, it advances both knowledge and practice by analyzing walking behavior at a small scale commensurate with walk trips and including relevant measures of the pedestrian environment. By themselves, the model results highlight important land use and transportation policy levels that could encourage 
walking. For instance, increasing the number of activity opportunities in a neighborhood center or installing sidewalks and connecting street grids along a suburban strip could encourage people to walk from further away, helping to overcome the significant distance barrier that walking faces.

More broadly, this research opens the door to potential extensions and planning applications. The next logical step in the pedestrian modeling framework (after pedestrian destination choice) is to examine the prediction of potential pedestrian routes or paths between walk-trip origins and destinations. Even without this next component, the existing work (when combined with the prior OTREC project) can be used to modify a regional travel demand model or operate as a standalone pedestrian planning tool. Either way, such a planning tool could help to inform pedestrian infrastructure investments, quantify mode shifts, improve transportation safety analyses, and provide better inputs to health impact assessments. Overall, these pedestrian models set the stage for future research and the development of useful practical planning tools. 


\subsection{INTRODUCTION}

There is growing support for improvements to the quality of the walking environment, including more investments to promote pedestrian travel. Also, there have long been calls for better analytical tools to aid in planning for non-motorized modes. Planners, engineers, policymakers and others seek improved tools to estimate levels of pedestrian demand that are sensitive to environmental and demographic factors at the appropriate scale. Such tools have the potential to inform pedestrian infrastructure investments; quantify mode shifts (and resulting changes in greenhouse-gas emissions); improve transportation safety analyses; and create outputs relevant to emerging issues of public health, economic development and sustainability.

Despite recent increased interest in planning for walking, current forecasting tools-namely regional travel demand models - incompletely represent pedestrian behaviors (Singleton \& Clifton, 2013). However, two recent advances have opened the door to significant innovations in pedestrian modeling: 1) the availability of spatially disaggregate travel behavior data (documenting walk trips more accurately); and 2) detailed data about the quality of the pedestrian environment (including pedestrian barriers and supports and fine-grained land use characteristics). Both advances allow pedestrian travel behavior to be modeled at an appropriate scale, catalyzing the development of improved pedestrian planning tools.

To this end, a previous Phase I Oregon Transportation Research and Education Consortium (OTREC) project ("Improving the Representation of the Pedestrian Environment in Travel Demand Models”) developed a robust pedestrian planning method for use in regional travel demand models (Clifton, Singleton, Muhs, Schneider \& Lagerwey, 2013). Utilizing a new measure of the pedestrian environment and a micro-level unit of analysis, the number of walk trips generated can be predicted with spatial acuity. This Phase 2 National Institute for Transportation and Communities (NITC) project builds upon the successes of the previous project and extends the pedestrian demand estimation tool's functionality. These efforts may expand the tool's utility to users beyond the travel demand modeling community, including other pedestrian planning stakeholders. This project is a continuing partnership between the Oregon Modeling Collaborative and Metro.

Specifically, this project incorporates a means to predict the distribution of walk trips generated (from the previously developed method) to destinations, at the same micro-level spatial scale. It develops predictive models of pedestrian destination choice behavior using statistical analysis. Notably, this method is sensitive to distance, the attractiveness of different destinations, supportive and deterring characteristics of the pedestrian environment, and socioeconomics of the pedestrian. The research design utilizes existing data resources, including a recent regional household travel survey and the wealth of detailed, spatially differentiated environmental data available throughout the Portland region.

This project builds off of a framework to better represent walking in travel demand models, introduced by the authors in a previous project (Clifton et al., 2013) and illustrated in Figure 1.1. 
The pedestrian modeling framework consists of four main steps, outlined below. Foremost, it increases the ability of regional travel models to represent walking within a trip-based structure without adding significant complexity or data requirements. It also has potential to be modified to function as a standalone tool for pedestrian planning at a variety of scales, and the destination choice step in particular may be amenable to inclusion in activity-based models.

1. Change the spatial unit of analysis for trip generation (all modes) from transportation analysis zones (TAZs) to pedestrian analysis zones (PAZs). Here, PAZs are uniform grid cells (in this application they have 264-foot (80m) sides).

2. Apply a walk-mode split model to estimate the number of walk trips produced in each PAZ. This binary logit model includes spatially disaggregate built environment and socioeconomic variables that measure relationships between walking and the physical environment.

3. Aggregate trips by vehicular modes (auto, transit and bicycle) to the zonal structure of the regional model (TAZs) and then proceed with the remaining stages for these modes in the regional model.

4. In parallel procedure, apply a destination choice model to distribute the number of walk trips produced in each PAZ (step 2) to destinations.

Steps 1-3 have been described previously in Phase I of this research (Clifton et al., 2013). Building upon the previous research, this report, Phase II, focuses on the fourth step and describes the development of the pedestrian destination choice model.

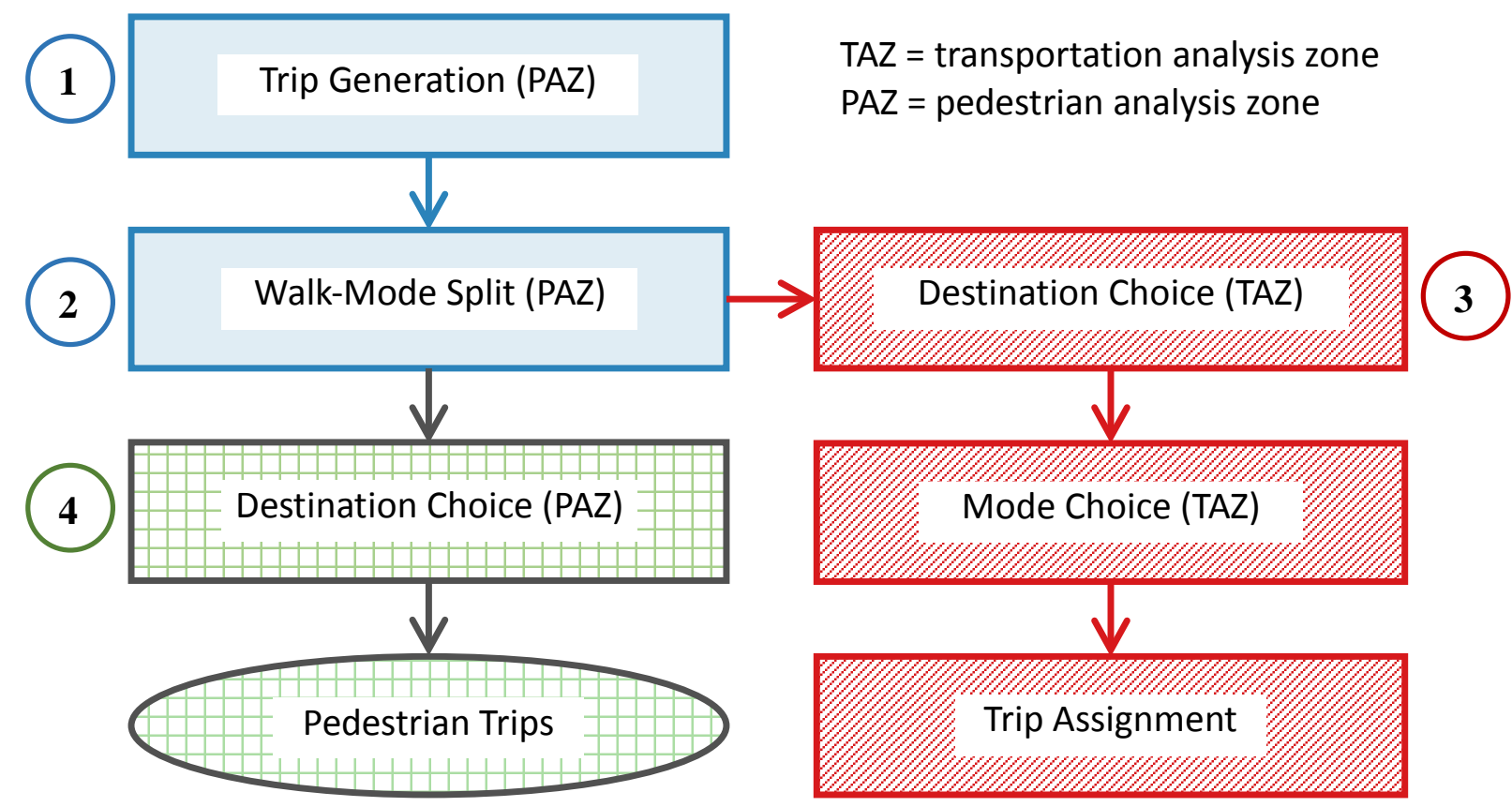

\section{All Person \\ Pedestrian Trips \\ Vehicular}

Figure 1.1 Framework to increase representation of walking in conventional travel demand models (Clifton et al., 2013) 
The destination choice work done in this project fits within a larger effort to improve pedestrian planning tools. For example, framework in Figure 1.1 could be extended, building from chosen walk-trip destinations to identify the spatial extent of potential pedestrian paths to those destinations. These methods could then be integrated with the products developed from the previous research and assembled to provide a standalone tool to estimate various aspects of pedestrian demand: trip generation, trip distribution and areas of potential pedestrian activity. The steps needed to do this are outlined in the Discussion section of this report. Such a tool would increase the arsenal of analytical methods available for regional demand modeling as well as pedestrian and safety analysis, health assessments and other pedestrian planning applications.

The remainder of this report is organized as follows: In the Background section, a literature review summarizes destination choice modeling and considerations for pedestrian behavior. The Methods and Data section describes the approach to modeling pedestrian destination choices and the data sources used. Then, results are presented from model estimation, followed by the results of model validation. Next, an application section provides an example of what is possible from implementing the model using a case study example. The report concludes with a discussion of implications for practice and opportunities for future work. 


\subsection{BACKGROUND}

Trip distribution, the linking of two trip ends, is the second step of traditional four-step travel demand models (for an overview, see Ortúzar \& Willumsen, 2011). In the first step of traditional four-step models and the pedestrian framework in Figure 1.1, models predict the number of trips that are produced by and/or attracted to (begin and/or end at) a particular place. The second step, trip distribution, completes these trips by linking trip ends, predicting the number of trips flowing between two places. Historically, trip distribution methods include growth factor methods and gravity model methods. More recently, practice is moving towards using destination choice models to distribute trips from origins to probable destinations.

Destination choice models are an application of the specific set of statistical analysis tools known as discrete choice models. Recall that discrete choice models are used to predict a decisionmaker's choice of one alternative from a finite set of alternatives (Koppelman \& Bhat, 2006). Destination choice models can have a similar model structure to the multinomial logit models often used for mode choice. However, unlike a mode choice problem where the set of choice alternatives (travel modes) can be reasonably defined, in destination choice problems the analyst does not know the actual set of alternatives (both the number and specific destinations) considered by the decision-maker. Accordingly, the main challenges in destination choice modeling are: 1) generating the choice set of alternatives, and 2) specifying variables.

Existing literature offers guidance for developing destination choice models, especially with respect to choice set generation (Pagliara \& Timmermans, 2009) and variable specification (BenAkiva \& Lerman, 1985; Bernardin, Koppelman \& Boyce, 2009; Borgers \& Timmermans, 1988; Pozsgay \& Bhat, 2001). Common options for constructing choice sets include: 1) using deterministic rules (Ortúzar \& Willumsen, 2011; Pagliara \& Timmermans, 2009); and 2) using a form of sampling of alternatives (Ben-Akiva \& Lerman, 1985; Lemp \& Kockelman, 2012). Some choice sets have been constructed with data on the perceived availability of alternatives (Ortúzar \& Willumsen, 2011; Pagliara \& Timmermans, 2009), but this information is difficult to collect and rare. Standard practice for the estimation of destination choice models involves a random sampling of alternatives. Alternatives are not typically individual homes or businesses; instead, the sampled alternatives are geographic aggregations of elemental destinations such as TAZs.

Regarding variable specification, destination choice models typically include, at a minimum, terms for impedance and size (Ben-Akiva \& Lerman, 1985; Bhat, Govindarajan \& Pulugurta, 1998). Impedance is usually operationalized in terms of distance or generalized cost (distance and cost converted to equivalent units). Size refers to the physical size or number of elemental destinations within a particular destination alternative/zone and is typically operationalized in terms of employment. Due to the use of aggregate alternatives, the size term must be included as a natural log term within the model; this nonlinear-in-parameters specification requires a special procedure for model estimation (Ben-Akiva \& Lerman, 1985; Daly, 1982). 
It is important to consider the unique determinants of walking when investigating pedestrian destination choice behavior. Research has identified a common set of built environment features that affect walking. Distance to destinations is often a strong factor (Saelens \& Handy, 2008). Walking has been positively associated with residential and employment density, land use mix, and connectivity (Ewing \& Cervero, 2010; Saelens \& Handy, 2008; Saelens, Sallis \& Frank, 2003). It may also be related to transit accessibility (Schneider, Arnold \& Ragland, 2009) and street-level characteristics like sidewalks (Rodríguez \& Joo, 2005). Thus, far more studies have analyzed mode choice or walk-trip frequency; few have looked solely at environmental correlates of pedestrian destination choice.

The current effort is unique since this is one of the first studies to focus on destination choices among pedestrians distinct from other modes. Some research lends insights to pedestrian destination choice behavior, with limitations. Borgers \& Timmermans’ 1986 study of pedestrian retail shopping trips found that trip distance and retail floor area had significant impacts on destination choice. However, the study was limited to a city center and did not test impacts of built environmental attributes. Eash (1999) found positive associations between a "pedestrian environment factor" (PEF) and destination choices in models of non-motorized trips in Chicago. However, the PEF variable was based solely on the number of census blocks in a sub-zoneonly a rough measure of the pedestrian environment-making it difficult to draw conclusions about behavior and policy implications. Khan, Kockelman and Xiong (2014) developed destination choice models for non-motorized trips and explored effects of many built environment measures, but despite parcel-level data being used for sequential trip generation and mode choice models, TAZ-level data were used in the destination choice step. The TAZ is a less desirable unit for evaluating pedestrian trips, which tend to be short and therefore are mostly intrazonal in a TAZ system.

Based on these unique aspects of pedestrian behavior and contributions of previous literature, our model development is guided by the following points:

- Distance sensitivity: Pedestrians are highly responsive to distance, so choice sets are constrained to local destinations based upon some threshold. Distance sensitivity likely varies by trip purpose.

- Pedestrian supports: Some built environment influences are unique to pedestrian travel, particularly when measured at a fine spatial scale around origins, destinations and along the potential route. Existing destination choice studies test pedestrian environment variables that are coarse in either definition (Eash, 1999) or geographic scale (Khan et al., 2014), leaving room for improvement. For example, this study incorporates the pedestrian index of the environment (PIE), a detailed and fine-grained measure developed previously by the authors (Clifton et al., 2013).

- Pedestrian barriers: Barriers or deterrents to walking such as steep slopes, higher traffic speeds and volumes, parking characteristics, and industrial-type employment may affect the choice of destination.

- Socioeconomic characteristics: Traveler characteristics like income or age may moderate some of these effects. 


\subsection{METHODS AND DATA}

In this section, the approach to destination choice models and the data used for this effort are described.

\subsection{METHODS}

\subsubsection{Modeling approach}

Our framework for pedestrian destination choice modeling is shown in Figure 3.1. It consists of three processes: 1) aggregating PAZs used in the trip generation step to slightly larger geographic zones called superPAZs, which are grids of 5x5 PAZs; 2) applying a destination choice model; and 3) allocating trips from superPAZs to PAZs within them. In section 3.1.2 we discuss the superPAZ zonal aggregation (step 1); in section 3.1.3 we document the methods for pedestrian destination choice models (step 2); and in section 3.1.4 the methods for allocating trips from superPAZs to PAZs are presented (step 3).

1. Aggregate PAZs to superPAZs

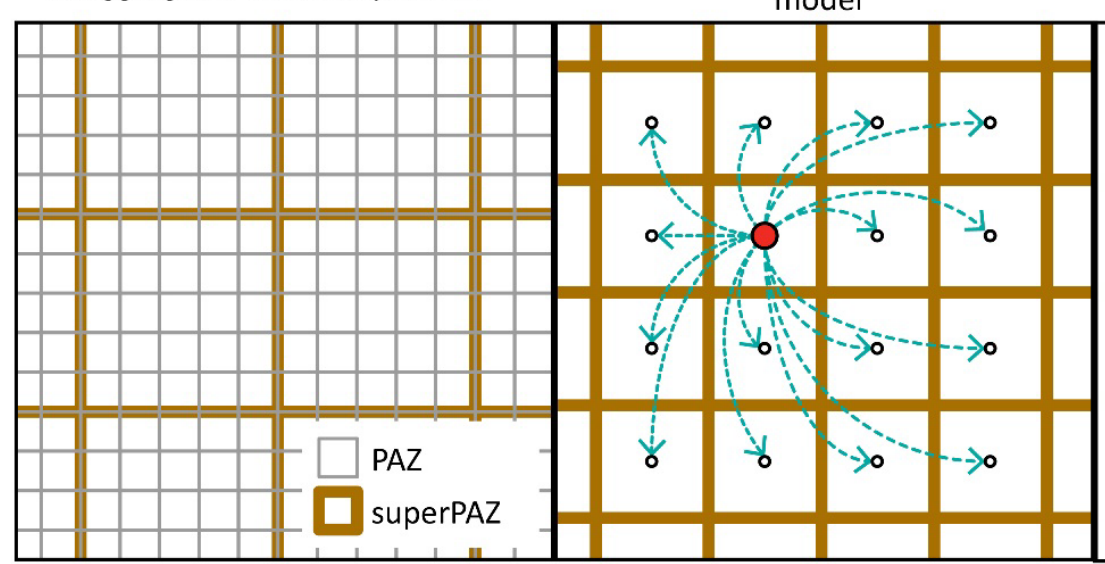

3. Allocate trips from each superPAZ to PAZs

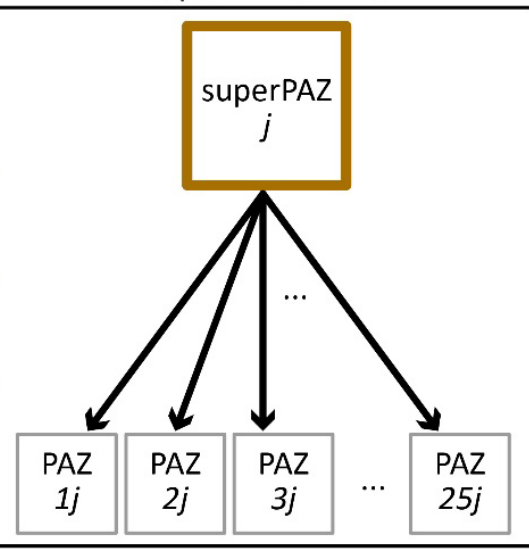

Figure 3.1 Framework for pedestrian destination choice

\subsubsection{Zonal aggregation}

To remedy the problems of representing walking using the large zonal structures (TAZs) found in most regional travel demand models, the pedestrian modeling framework (in Phase I) developed a new zonal structure using pedestrian analysis zones (PAZs). The PAZs are 264-footby-264-foot (80m-by-80m) raster grid cells; thus, the edges of a PAZ represent a one-minute walking distance at $3.0 \mathrm{mph}(4.8 \mathrm{kph})$. This choice of geography is one of convenience; the same grid cells were already being used by Metro for other planning tasks. Using a compatible spatial unit populated with archived data is crucial for the long-term success and usefulness of the pedestrian modeling framework. In contrast to blocks or parcels, grid cells have a uniform size, regardless of land use density, that makes zonal calculations and comparisons easier. Over 1.5 
million PAZs (compared to only 2,147 TAZs) cover the four counties included in Metro's model of the Portland region: Multnomah, Clackamas and Washington counties in Oregon and Clark County, WA.

The destination choice models used aggregations of 25 (5x5) PAZs called superPAZs. This geographic unit was chosen over individual PAZs to lessen computation times for data processing and model estimation.

\subsubsection{Destination choice models}

To examine destination choice behavior among pedestrians, we estimated multinomial logit destination choice models to predict the probability $P$ of a walk trip going from production zone $i$ to attraction zone $j$, given a choice set of attraction zones $K$, according to the following equation:

$$
P_{j, i}=\frac{e^{V_{j i, i}}}{\sum_{k \in K^{e}} e^{V_{k, i}}}
$$

Destination alternatives consisted of superPAZs. We considered several choice set generation methods, including simple random sampling, stratified importance sampling (Ben-Akiva \& Lerman, 1985) and strategic sampling (Lemp \& Kockelman, 2012). For now, we generated choice sets consisting of a simple random sample of 10 superPAZs (including the chosen zone) with centroids located within a 3 mile $(4.8 \mathrm{~km})$ network distance of the production zone. More than $99 \%$ of observed walk trips in our estimation dataset were less than 3 miles in length.

\subsubsection{Destination choice allocation models}

Methodological options for step 3 include using a gravity model, applying the superPAZ-based destination choice model, or estimating a new PAZ-allocation model. For the purposes of this project, we simply applied the destination choice models estimated using superPAZs to the allocation of trips from superPAZs to PAZs.

\subsection{DATA}

\subsubsection{Pedestrian travel behavior}

To estimate the pedestrian destination choice models, we used travel behavior data from the 2011 Oregon Household Activity Survey, or OHAS (OMSC, 2011). One-day travel diaries were collected on weekdays from April to December 2011 for 6,108 households living in the fourcounty Portland metropolitan area, yielding 55,878 full trips (excluding access and egress trips). The OHAS data contained 4,511 walk trips (8\%, unweighted); this quantity underestimated the total amount of walking by excluding access/egress trips such as those associated with using public transportation. Trip origins and destinations were located using addresses and assigned to PAZs and superPAZs. Of walk trips, 44\% were TAZ-intrazonal. By comparison, only 25\% were superPAZ-intrazonal and 9\% PAZ-intrazonal, highlighting another advantage of using smaller spatial units to represent walking. Walk trips and destination choice models were segmented by 
six trip purposes: home-based work (HBW), shopping (HBS), recreation (HBR), and other (HBO); and non-home-based work (NHBW) and non-work (NHBNW). Home-based school trips were not modeled because of the complexities of school assignment policies.

\subsubsection{Built environment}

Destination choice utility equations were specified using measures of impedance $\operatorname{Imp}$, a $\log$-sum of size terms $s$, pedestrian trip supports $p$ and barriers $b$, and traveler characteristics $c$ as shown in the following utility equation and detailed below:

$$
V_{j, i}=\sum_{c \in C} \beta_{I m p, c} I m p_{i j} T C_{c}+\beta_{s i z e} \ln \left[\sum_{s \in S}\left(e^{\beta_{x}} \text { Size }_{s, j}\right)\right]+\sum_{p \in P}\left(\beta_{p} \operatorname{Support}_{p, j}\right)+\sum_{b \in B}\left(\beta_{b} \text { Barrier }_{b, j}\right)
$$

- Impedance $\left(\operatorname{Im} p_{i j}\right)$ : As a measure of impedance, we calculated the shortest path distance (in miles) between the centroid of zones $i$ and $j$ along a network that included the complete street network and major off-street paths.

- Size/attractiveness (Size $e_{s, j}$ ): Size terms included zonal employment by type and (for some purposes) the number of households. Employment categories were retail trade; service; finance/insurance/real estate; government; agriculture/forestry/mining; construction; manufacturing; transportation/communications/utilities; and wholesale trade. Employment data came from the 2009 Quarterly Census of Employment and Wages database (BLS, 2009). Consistent with destination choice practices, size terms were summed and logged, yielding a nonlinear-in-parameters specification. Internal size coefficients were exponentiated to prevent negative parameter estimates. Size terms were scaled such that the parameter for service employment (the largest category) equaled 1 $\left(e^{0}\right)$.

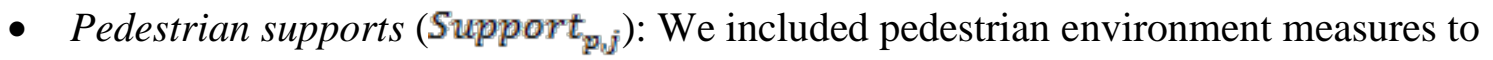
represent supportive conditions in the destination zone. The primary measure of a supportive pedestrian environment was the pedestrian index of the environment, or PIE (Clifton et al., 2013). The PIE, a 20-100 score calibrated to walking behavior, captured the effects of activity density, block density, sidewalk density, transit access, neighborhood-oriented businesses and other factors (Singleton, Schneider, Muhs \& Clifton, 2014). Supports also included the presence of parks for some purposes.

- Pedestrian barriers (Barrier B $_{b j}$ ): Barriers to pedestrian travel included the mean slope in the destination zone, the presence of freeways and the proportion of industrial-type employment (not retail, service, finance or government jobs) as a proxy for industrial land uses.

- Traveler characteristics $\left(T C_{c}\right)$ : We also examined the interaction of impedance with certain traveler characteristics from OHAS data, including households with children and auto ownership.

Table 3.1 summarizes descriptive statistics for the variables used in pedestrian destination choice modeling. Descriptive statistics for destination-specific variables include only those zones that were chosen. 
Table 3.1 Descriptive statistics for pedestrian destination choice model variables

\begin{tabular}{lrrrrrrr}
\hline & & HBW & HBS & HBR & HBO & NHBW & NHBNW \\
\hline Sample Size & & 305 & 405 & 643 & 1108 & 732 & 705 \\
\hline Impedance & & & & & & & \\
Distance (miles) & Mean (SD) & $0.75(0.79)$ & $0.57(0.49)$ & $0.53(0.51)$ & $0.51(0.49)$ & $0.38(0.39)$ & $0.41(0.46)$ \\
\hline Size/attractiveness & & & & & & & \\
Retail jobs (\#) & Mean (SD) & $223(537)$ & $299(431)$ & $62(202)$ & $106(259)$ & $845(1053)$ & $419(760)$ \\
Service jobs (\#) & Mean (SD) & $398(971)$ & $216(590)$ & $102(331)$ & $136(441)$ & $1689(1863)$ & $611(1313)$ \\
Finance jobs (\#) & Mean (SD) & $151(479)$ & $83(336)$ & $24(99)$ & $43(211)$ & $827(1147)$ & $200(536)$ \\
Government jobs (\#) & Mean (SD) & $207(668)$ & $76(227)$ & $28(129)$ & $55(241)$ & $904(1484)$ & $308(799)$ \\
All other jobs (\#) & Mean (SD) & $66(126)$ & $31(71)$ & $30(85)$ & $35(95)$ & $165(183)$ & $75(143)$ \\
Households (\#) & Mean (SD) & $206(208)$ & $324(442)$ & $174(160)$ & $197(197)$ & $325(324)$ & $283(337)$ \\
\hline Pedestrian supports & & & & & & & \\
Park (yes) & \# (\%) & $182(60 \%)$ & $257(63 \%)$ & $480(75 \%)$ & $677(61 \%)$ & $555(76 \%)$ & $458(65 \%)$ \\
PIE, mean & Mean (SD) & $51(27)$ & $56(26)$ & $44(22)$ & $46(26)$ & $75(25)$ & $58(28)$ \\
\hline Pedestrian barriers & & & & & & & \\
Slope (degrees), mean & Mean (SD) & $1.63(1.45)$ & $1.27(0.90)$ & $1.83(1.75)$ & $1.37(0.88)$ & $1.38(0.84)$ & $1.44(1.13)$ \\
Freeway (yes) & \# (\%) & $33(11 \%)$ & $19(5 \%)$ & $33(5 \%)$ & $61(6 \%)$ & $106(14 \%)$ & $99(14 \%)$ \\
Industrial jobs (prop.) & Mean (SD) & $0.10(0.16)$ & $0.06(0.1)$ & $0.19(0.26)$ & $0.14(0.21)$ & $0.07(0.13)$ & $0.09(0.16)$ \\
\hline Traveler characteristics & & & & & & & \\
Auto ownership (yes) & \# (\%) & $237(78 \%)$ & $301(74 \%)$ & $589(92 \%)$ & $1019(92 \%)$ & $689(94 \%)$ & $592(84 \%)$ \\
Children (yes) & \# (\%) & $91(30 \%)$ & $117(29 \%)$ & $279(43 \%)$ & $628(57 \%)$ & $222(30 \%)$ & $292(41 \%)$ \\
\hline
\end{tabular}




\subsection{MODELING RESULTS}

\subsection{MODEL ESTIMATION}

\subsubsection{Destination choice models}

Models were estimated using Python Biogeme Version 2.3 (Bierlaire, 2003). Model estimation proceeded sequentially, adding all of the variables in each of type and removing or grouping insignificant parameters for parsimony (among impedance and size variables only) before considering the next variable type.

Model estimation results for the six purpose-specific destination choice models are presented in Table 4.1. McFadden's adjusted pseudo- $\mathrm{R}^{2}$ values ranged from 0.416 for home-based recreation to 0.680 for home-based shopping purposes. Results were consistent with intuition and previous studies of pedestrian behavior.

Table 4.1 Results of pedestrian destination choice models

\begin{tabular}{|c|c|c|c|c|c|c|c|c|c|}
\hline \multirow[b]{2}{*}{ Variable } & \multicolumn{3}{|c|}{$\begin{array}{r}\text { Home-based } \\
\text { work (HBW) }\end{array}$} & \multicolumn{3}{|c|}{$\begin{array}{r}\text { Home-based } \\
\text { shopping (HBS) }\end{array}$} & \multicolumn{3}{|c|}{$\begin{array}{r}\text { Home-based } \\
\text { recreation (HBR) }\end{array}$} \\
\hline & $B$ & $S E$ & $p$ & $B$ & $S E$ & $p$ & $B$ & $S E$ & $p$ \\
\hline Distance (miles) & -- & -- & -- & -- & -- & -- & -- & -- & -- \\
\hline Distance (miles) $\times$ Auto (yes) & -1.35 & 0.124 & 0.00 & -- & -- & -- & -- & -- & -- \\
\hline Distance (miles) $\times$ Auto (no) & -0.96 & 0.182 & 0.00 & -- & -- & -- & -- & -- & -- \\
\hline Distance (miles) $\times$ Child (yes) & -- & -- & -- & -2.26 & 0.174 & 0.00 & -1.75 & 0.074 & 0.00 \\
\hline Distance (miles) $\times$ Child (no) & -- & -- & -- & -1.52 & 0.140 & 0.00 & -1.51 & 0.063 & 0.00 \\
\hline Size terms (ln) & 0.51 & 0.074 & 0.00 & 0.91 & 0.089 & 0.00 & 0.05 & 0.019 & 0.01 \\
\hline Retail jobs (\#) & -- & -- & -- & 5.5 & 0.71 & 0.00 & 6.5 & 1.36 & 0.00 \\
\hline Finance jobs (\#) & -- & -- & -- & -- & -- & -- & -- & -- & -- \\
\hline Government jobs (\#) & -- & -- & -- & -- & -- & -- & 17.1 & 5.65 & 0.00 \\
\hline Retail + government jobs (\#) & -- & -- & -- & -- & -- & -- & -- & -- & -- \\
\hline Retail + finance + government jobs (\#) & 2.0 & 0.85 & 0.02 & -- & -- & -- & -- & -- & -- \\
\hline All other jobs (\#) & 0.0 & -- & -- & 0.0 & -- & -- & 0.0 & -- & -- \\
\hline Households (\#) & -- & -- & -- & -- & -- & -- & -3.2 & 1.34 & 0.02 \\
\hline Park (yes) & -- & -- & -- & -- & -- & -- & 0.46 & 0.127 & 0.00 \\
\hline PIE, mean & 0.030 & 0.010 & 0.00 & -0.014 & 0.012 & 0.24 & 0.011 & 0.007 & 0.11 \\
\hline Slope (degrees), mean & -0.12 & 0.079 & 0.15 & -0.20 & 0.100 & 0.05 & -0.05 & 0.049 & 0.28 \\
\hline Freeway (yes) & -0.30 & 0.260 & 0.25 & -1.02 & 0.350 & 0.00 & -0.17 & 0.213 & 0.43 \\
\hline Industrial jobs (proportion) & -0.99 & 0.480 & 0.04 & -1.74 & 0.609 & 0.00 & -0.09 & 0.205 & 0.66 \\
\hline Sample size (\# walk trips) & & & 305 & & & 405 & & & 643 \\
\hline Initial log-likelihood & & -65 & 4.163 & & & 4.806 & & $-1,4$ & 8.715 \\
\hline Final log-likelihood & & & 1.460 & & & 8.303 & & & 0.664 \\
\hline McFadden’s adjusted pseudo-R ${ }^{2}$ & & & 0.453 & & & 0.680 & & & 0.416 \\
\hline
\end{tabular}


Table 4.1 (continued)

\begin{tabular}{|c|c|c|c|c|c|c|c|c|c|}
\hline \multirow[b]{2}{*}{ Variable } & \multicolumn{3}{|c|}{$\begin{array}{l}\text { Home-based } \\
\text { other (HBO) }\end{array}$} & \multicolumn{3}{|c|}{$\begin{array}{r}\text { Non-home-based } \\
\text { work (NHBW) }\end{array}$} & \multicolumn{3}{|c|}{$\begin{array}{r}\text { Non-home-based } \\
\text { non-work (NHBNW) }\end{array}$} \\
\hline & $B$ & $S E$ & $p$ & $B$ & $S E$ & $p$ & $B$ & $S E$ & $p$ \\
\hline Distance (miles) & -1.94 & 0.062 & 0.00 & -1.42 & 0.067 & 0.00 & -1.45 & 0.054 & 0.00 \\
\hline Distance (miles) × Auto (yes) & -- & -- & -- & -- & -- & -- & -- & -- & -- \\
\hline Distance (miles) × Auto (no) & -- & -- & -- & -- & -- & -- & -- & -- & -- \\
\hline Distance (miles) × Child (yes) & -- & -- & -- & -- & -- & -- & -- & -- & -- \\
\hline Distance (miles) × Child (no) & -- & -- & -- & -- & -- & -- & -- & -- & -- \\
\hline Size terms (ln) & 0.40 & 0.034 & 0.00 & 0.36 & 0.054 & 0.00 & 0.39 & 0.055 & 0.00 \\
\hline Retail jobs (\#) & -- & -- & -- & 5.5 & 0.66 & 0.00 & 5.5 & 1.05 & 0.00 \\
\hline Finance jobs (\#) & -- & -- & -- & 2.5 & 1.12 & 0.03 & -- & -- & -- \\
\hline Government jobs (\#) & -- & -- & -- & -- & -- & -- & 3.4 & 1.23 & 0.01 \\
\hline Retail + government jobs (\#) & 3.8 & 0.57 & 0.00 & -- & -- & -- & -- & -- & -- \\
\hline Retail + finance + government jobs (\#) & -- & -- & -- & -- & -- & -- & -- & -- & -- \\
\hline All other jobs (\#) & 0.0 & -- & -- & 0.0 & -- & -- & 0.0 & -- & -- \\
\hline Households (\#) & -2.0 & 0.87 & 0.02 & -- & -- & -- & 0.8 & 1.26 & 0.52 \\
\hline Park (yes) & 0.12 & 0.094 & 0.22 & -- & -- & -- & -- & -- & -- \\
\hline PIE, mean & 0.025 & 0.007 & 0.00 & 0.015 & 0.007 & 0.02 & 0.017 & 0.006 & 0.01 \\
\hline Slope (degrees), mean & -0.43 & 0.062 & 0.00 & -0.16 & 0.056 & 0.01 & -0.06 & 0.051 & 0.24 \\
\hline Freeway (yes) & 0.10 & 0.191 & 0.60 & -0.14 & 0.166 & 0.40 & 0.26 & 0.159 & 0.10 \\
\hline Industrial jobs (proportion) & -0.40 & 0.224 & 0.08 & -1.65 & 0.436 & 0.00 & -0.24 & 0.350 & 0.50 \\
\hline Sample size (\# walk trips) & & & 1,108 & & & 732 & & & 705 \\
\hline Initial log-likelihood & & $-2,5$ & 1.171 & & $-1,6$ & 7.748 & & $-1,5 \varepsilon$ & 9.681 \\
\hline Final log-likelihood & & $-1,1$ & 0.632 & & & 5.095 & & & 5.561 \\
\hline McFadden's adjusted pseudo- $\mathrm{R}^{2}$ & & & 0.526 & & & 0.585 & & & 0.544 \\
\hline
\end{tabular}

Distance was a significant deterrent when choosing a destination: a 1 mile $(1.6 \mathrm{~km})$ increase in network distance to a particular destination yielded about an $80 \%$ decrease $\left(e^{B_{\text {imp }}}-1\right)$ in the odds of choosing that destination. The average sensitivity to a 1 mile increase in distance ranged from a $62 \%$ decrease in odds for HBW walk trips (for zero-vehicle households) to a $90 \%$ decrease in odds for HBS walk trips (for households with children). Distance was a stronger deterrent to walking for HBS and HBO trips, while people were willing to walk further from home to get to work than for other purposes. For HBO, NHBW and NHBNW walk trips, there were no significant interactions between distance and the traveler characteristics of auto ownership and children. There was a significant distance-auto ownership interaction for HBW walk trips: people in zero-car households were less sensitive to distance than people from households that owned at least one car. There were also significant distance-children interactions for HBS and HBR walk trips: people in households with children were more sensitive to distance.

Measures of the size of destinations were significant positive predictors of walk-trip destination choice: doubling the number of jobs and households in a zone for several purposes (HBW, HBO, NHBW, NHBNW) yielded a $28-42 \%$ increase $\left(2^{B_{\text {size }}}-1\right)$ in the odds of choosing that destination zone (elasticities were 0.36-0.51). Destination choice for HBR walk trips was not strongly influenced by the destination zone size (elasticity was 0.05 ). However, the destination choice odds for HBS walk trips were almost perfectly elastic with respect to employment (0.91); doubling the number of jobs increased the odds by $88 \%$. The destination choice models also estimated the relative attractiveness of different types of employment or households for different purposes. For example, the number of retail jobs was overwhelmingly the dominant attractive 
force for HBS walk trips: one additional retail job was worth about $230\left(e^{B_{s}}\right)$ additional jobs of other types.

Supportive pedestrian environments in destination zones also attracted walk trips: A 10-point increase in the PIE score of a particular destination for NHBW and NHBNW purposes yielded about a $16-18 \%$ increase $\left(e^{10-B_{p}}-1\right)$ in the odds of choosing that destination. The average sensitivity to a 10-point increase in PIE was highest for HBW (a 34\% increase in odds) and HBO (a 28\% increase in odds) walk trips. PIE was not a significant predictor of pedestrian destination choice for HBW or HBR purposes. However, for HBR walk trips, the presence of a park increased the odds of choosing that destination zone by $58 \%$.

On the other hand, barriers to pedestrian travel deterred walking to some destinations. The mean slope (in degrees) in a destination zone was associated with decreased odds of choosing that zone for several walk-trip purposes (HBS, HBO, NHBW). In addition, the percentage of industrialtype jobs was negatively associated with pedestrian destination choice, significantly for four walk-trip purposes (HBW, HBS, HBO, NHBW). The presence of a freeway was a significant deterrent to HBS walk-trip destination choice.

The model estimation results also suggested some important tradeoffs between attributes of alternatives in the pedestrian destination choice problem, as shown in Figure 4.1. Comparing modeled sensitivities to size versus impedance, people were willing to walk longer distances to reach destinations with more jobs/households. For example, people were willing to walk 0.260.41 miles $(0.41-0.67 \mathrm{~km})$ further to reach destinations with twice as many jobs for HBW and HBS purposes. People were also willing to walk longer distances to reach destinations with more attractive pedestrian environments: $0.11-0.31$ miles $(0.17-0.50 \mathrm{~km})$ further to destinations 10 points higher on the PIE scale. Furthermore, improving the pedestrian environment of a destination was equivalently attractive to increasing the number of jobs/households located there. Increasing a destination's PIE score by 10 points was equivalent to increasing the number of jobs/households there by $52-85 \%$. 


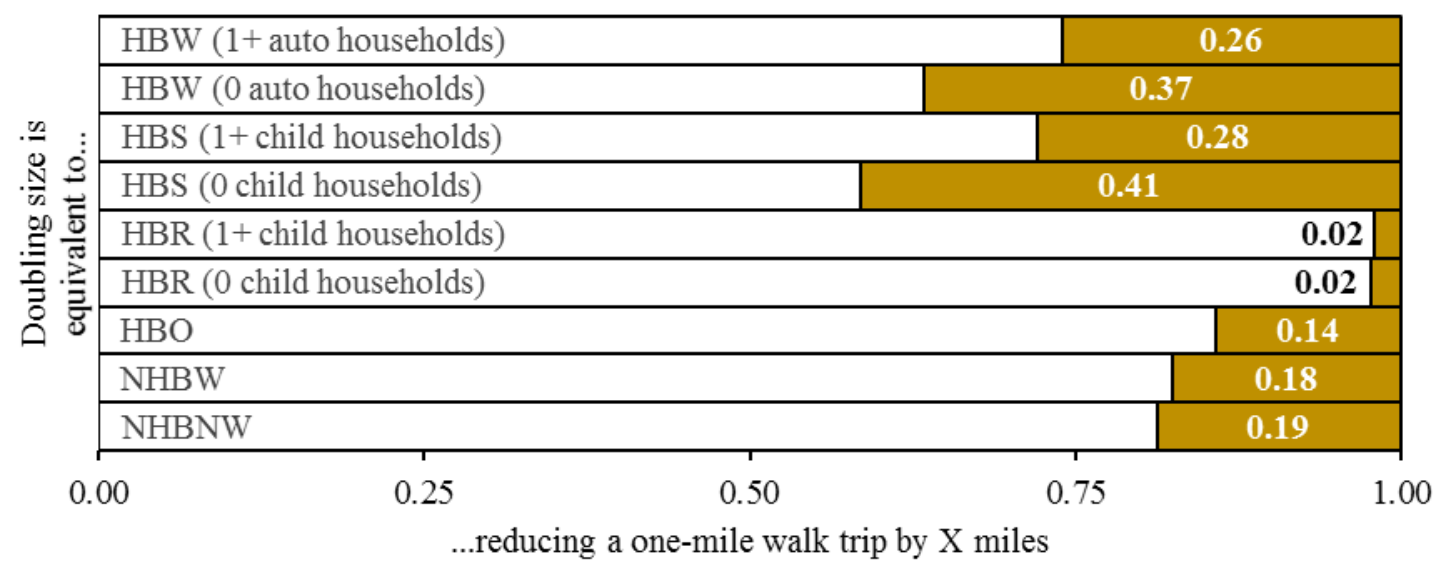
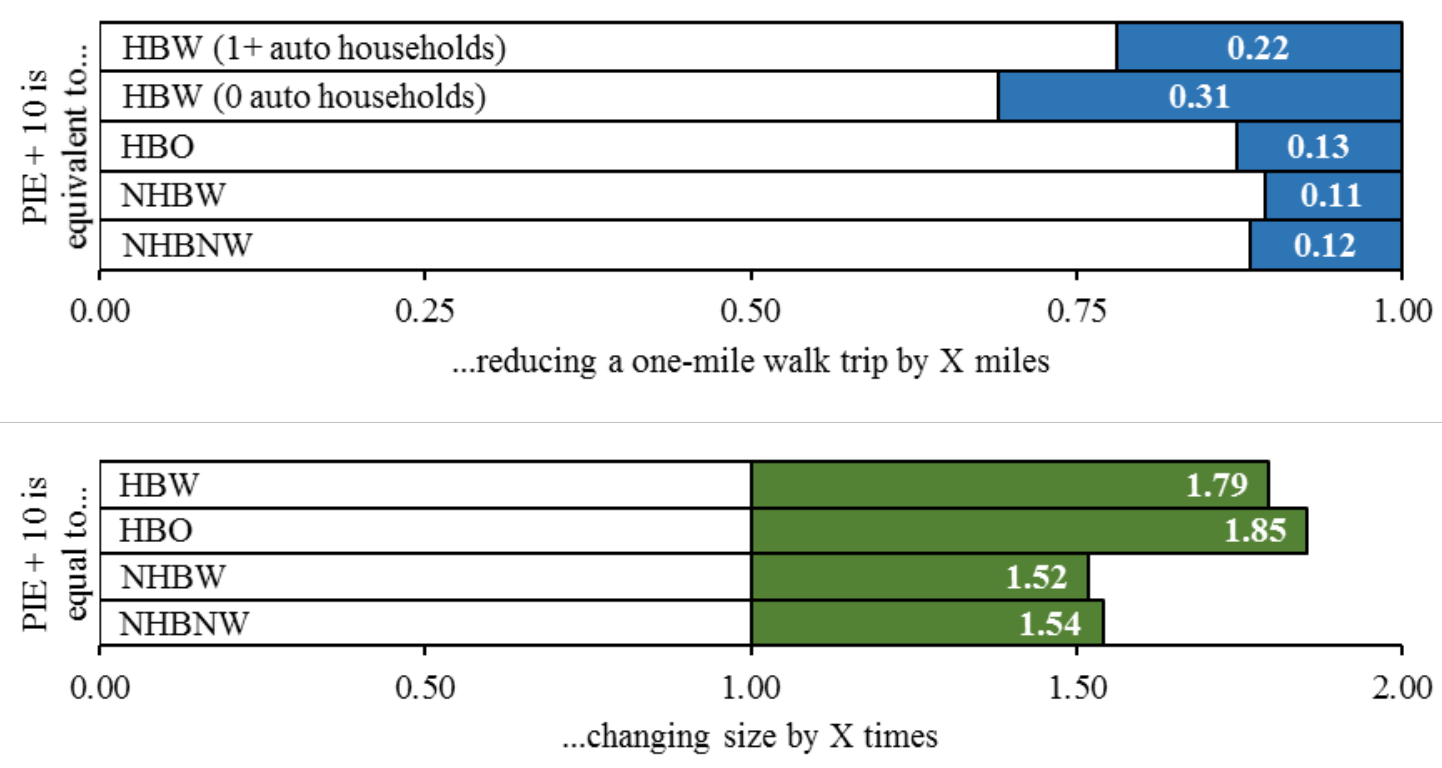

Figure 4.1 Relative sensitivities of pedestrian destination choice attributes

\subsubsection{Destination choice allocation models}

Because we did not estimate destination choice PAZ allocation models and, instead, applied superPAZ-based destination choice models, the estimated models are identical to those in Table 4.1. There is one exception: the impedance variable (distance) was not used.

\subsection{MODEL VALIDATION}

To assess the validity of the model, we applied the destination choice models to $100 \%$ of our estimation data (OHAS walk trips). In each case, the destination zone with the highest probability was considered the modeled choice. The assessment relied on a series of validation metrics, comparing our modeled destinations to the correct destinations actually chosen:

- Percent correct: The percentage of trips assigned to the correct destination superPAZ; 
- Modeled probability: The modeled probability of selecting the correct destination superPAZ (Note: one could consider the model residuals to be 1 minus these values);

- Trip length: The predicted walk-trip length based on the modeled destination choice.

Figure 4.2 displays validation results for the percent-correct metric, while Figure 4.3 shows the probability-correct validation results. Figure 4.4 compares the modeled versus actual average trip length of walk trips by purpose.

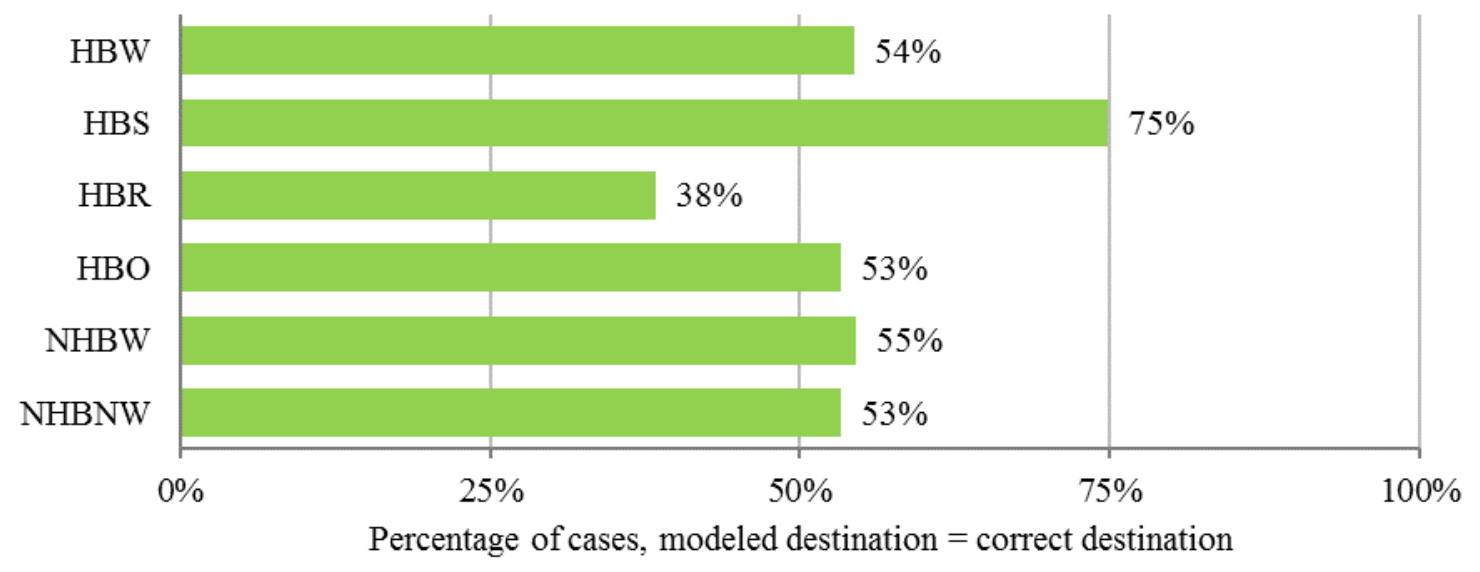

Figure 4.2 Percentage of trips where modeled destination was correct, by trip purpose

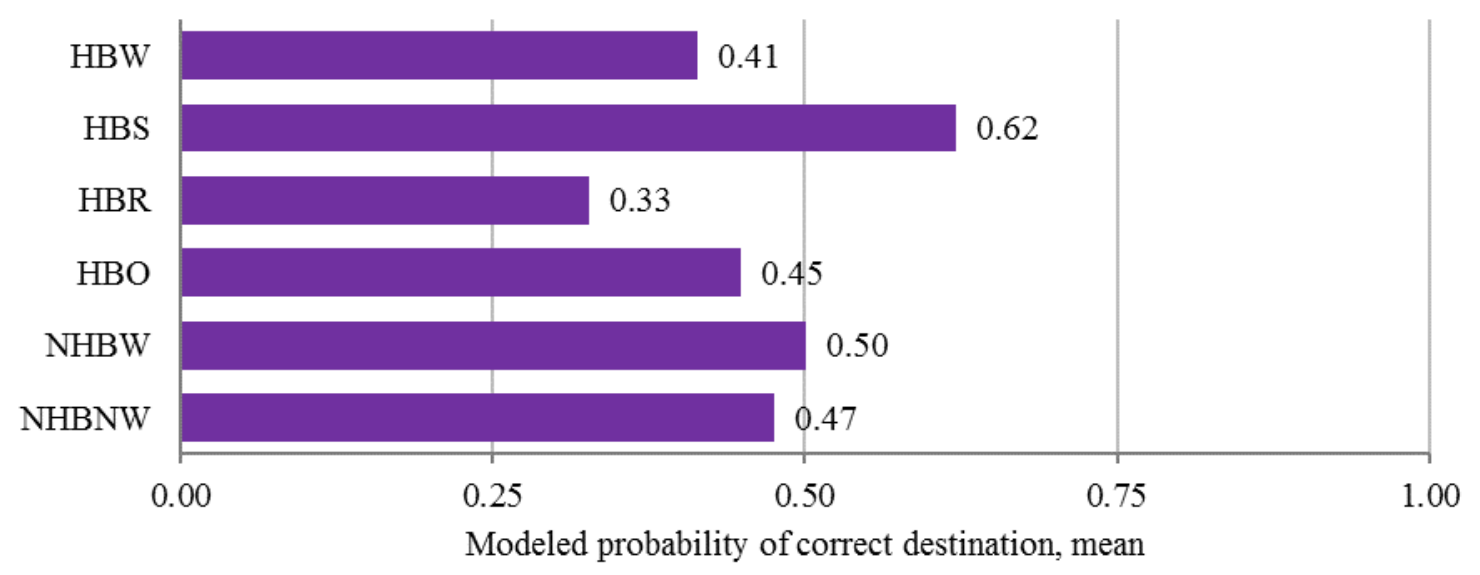

Figure 4.3 Modeled probability of selecting the correct destination, mean, by trip purpose 


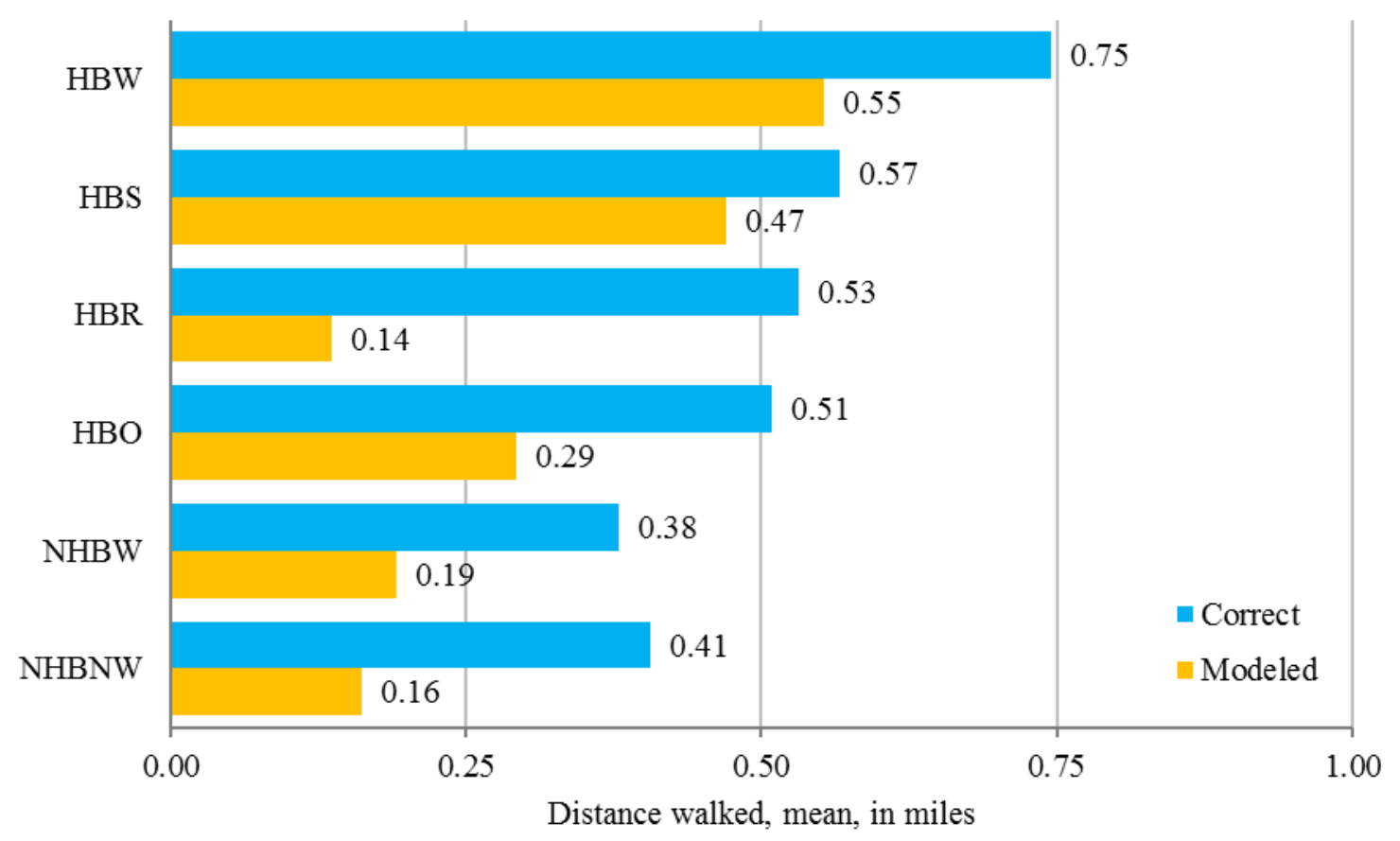

Figure 4.4 Walk-trip length (miles) for modeled and correct destinations, mean, by trip purpose

Validation results for the percent-correct metric indicate that our pedestrian destination choice models performed relatively well, with some exceptions. For all trip purposes except for HBR, the model predicted the selected destination superPAZ in more than half the cases. For the HBS purpose, $75 \%$ of walk trips were assigned to the correct destination; however, only 38\% of HBR walk trips were assigned correctly. Having more than half of walk trip destinations correctly predicted is a relatively good result. Consider: superPAZs are small geographic units; only 25\% of walk trips were intrazonal to superPAZs; and each model included only a handful of independent variables.

Further support for the relatively strong performance of the models comes from the modeledprobability validation metric. For most purposes, the selected destination had a high probability of being chosen by the destination choice models. The mean modeled probability of the correct destination was typically in the $0.41-0.50$ range, with a low of 0.33 (HBR) and a high of 0.62 (HBS). These relatively high probabilities (compared to a random probability of 0.10 ) indicate that the correct destination had a relatively good chance of being chosen, even if it was not the modeled destination.

The pedestrian destination choice models performed less strongly when validating walk-trip lengths by purpose. Across the board, the modeled destination zones were closer to the production zones than the actual destinations zones chosen, yielding shorter average walk trips. Not surprisingly, differences in walk-trip lengths were bigger for HBR trips and smaller for HBS trips. Future work should investigate why the destination choice models resulted in underestimated walk-trip distances for all purposes. Additional work could try to improve the performance of the HBR model, in particular. 


\subsection{MODEL APPLICATION}

As part of the Phase I project (Clifton et al., 2013), we applied steps 1-3 of the pedestrian modeling framework in Figure 1.1 to a subset of Metro's region that covered part of north and northeast Portland. This process involved several steps. First, we developed base year (2010) PAZ-level input data, including households by size, income and age; employment by category; our PIE measure of the pedestrian environment; and other zonal characteristics. Next, we applied Metro's existing trip generation model equations (Metro, 2008) to the PAZ input data to generate estimates of the number of daily trips produced in each PAZ for eight different purposes. Finally, we applied our estimated walk-mode split models to the trip generation outputs to calculate the proportion and number of walk trips generated in each PAZ by purpose. Figure 5.1 presents a map of HBO walk-trip productions for the subset area. See the Phase I report (Clifton et al., 2013) for details about this process.

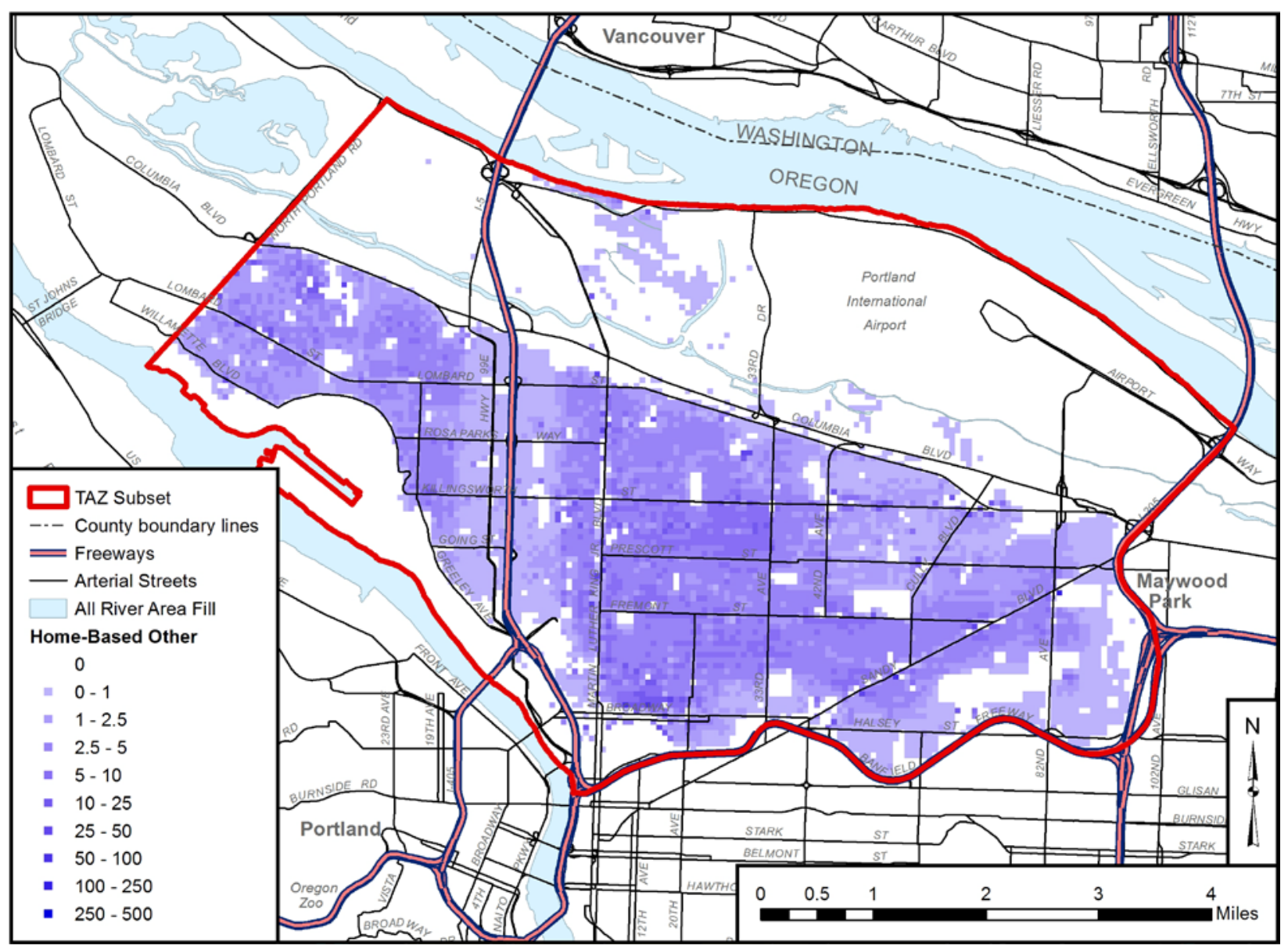

Figure 5.1 Predicted HBO walk-trip productions for a subset of Portland-area PAZs

For this Phase II project, we continued with the application of the pedestrian modeling framework by implementing step 4—destination choice—for the same subset study area. This 
process involved first aggregating our input data from PAZs to superPAZs and then applying our estimated pedestrian destination choice models. The first-stage outputs from the destination choice models are, for every superPAZ, the proportion of walk trips of a particular purpose produced from the superPAZ that are attracted to all other superPAZs. Figure 5.2 displays a map of HBO walk-trip destination choice model results for a zone located in a neighborhood commercial district.

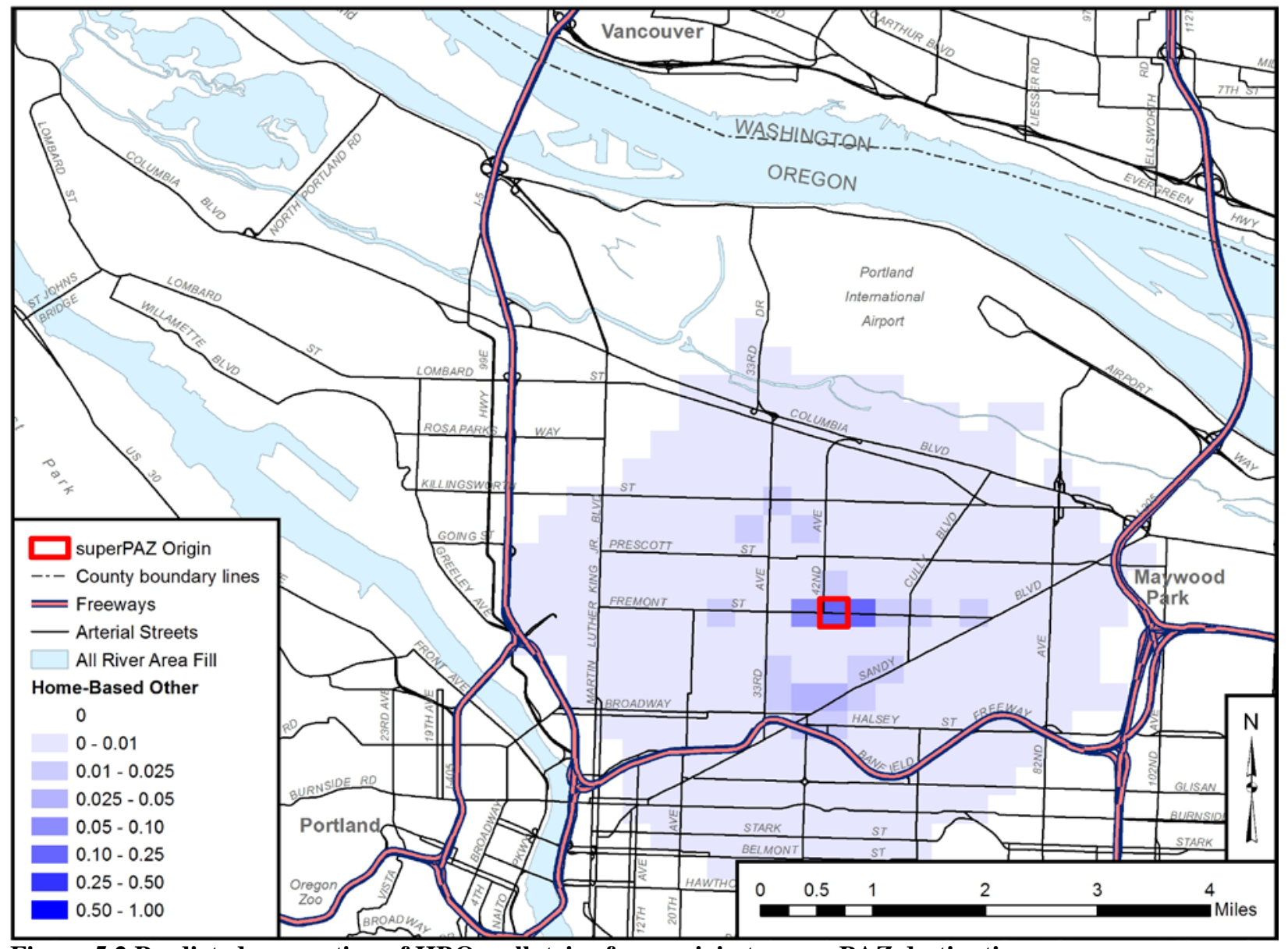

Figure 5.2 Predicted proportion of HBO walk trips from origin to superPAZ destinations

Several different kinds of important information can be obtained by summarizing the results of applying the pedestrian destination choice models, especially when combined with the results of applying the trip generation and walk-mode split models from Phase I. First, walk model and destination choice model results can be combined to calculate the predicted number of walk trips from each zone to each other zone, not simply the proportion of walk trips. Next, these estimates can be aggregated to calculate the number of walk trips attracted to each zone. Furthermore, now that the model predicts the location of both ends of a walk trip, approximate walking distances can be calculated and summarized by residents of an area or for all walking activity that occurs in an area or crosses a cordon. There are numerous uses for such important information on walking activity, as described in the discussion section below. 


\subsection{DISCUSSION}

\subsection{FINDINGS}

This paper is one of the first to explore the destination choice dimension of pedestrian travel behavior. Its primary unique contributions are a focus exclusively on pedestrian travel, analysis at a pedestrian scale and inclusion of pedestrian-relevant variables. More specifically, our analysis relies on a uniform 80-meter-by-80-meter grid zonal system —a size commensurate with the spatial extent of walk trips - and includes traveler characteristics, pedestrian environment variables, and common destination choice factors (impedance and size).

Results suggest important behavioral influences related to walking. Distance is the major influence on pedestrian destination choice. Sensitivity to distance varied across trip purposes and was affected by traveler characteristics such as auto ownership and children in the household. The size or attractiveness of destinations is also important for walking behavior; people were willing to walk further to reach zones with more jobs, especially retail jobs, particularly for HBS trips. The built environment also matters, as more attractive pedestrian environments supported walking while terrain and industrial areas deterred walking.

Our results also highlight the importance of a few land use and transportation policy-levers that may act to encourage walking. As Figure 4.1 indicates, increasing the number of activity opportunities (as measured by employment) in a regional center or neighborhood commercial corridor could encourage people to walk from further away to reach that area. However, the urban design of such areas is also important; walking to and within suburban strip developments could be made more attractive by installing sidewalks, connecting street grids, and encouraging neighborhood-oriented businesses, all key components of our PIE measure.

\subsection{FUTURE WORK}

In this paper, the destination choice dimension of pedestrian behavior was chosen for study because the effort is one component of a larger pedestrian forecasting model. The model operates within a modification of the common four-step travel demand modeling process. In the pedestrian forecasting model, trips are first generated, then mode is chosen, and then the trips are distributed. As such, choice of destination for an activity is considered sequentially after the trip is generated and the walk mode is chosen. In reality, destination choices are probably considered along with choices of mode, time of day, activity, and whether to travel at all. This larger issue affects both trip- and activity-based travel forecasting models and has been questioned by many authors (e.g., Pas, 1985). Future work could address this concern and others. Particularly, there is a need for more qualitative research on pedestrian travel behavior, including how destinationand route-level characteristics affect choices for pedestrians. This work could build upon the large body of research on mode choice and motivations for walking, and could help inform quantitative route-level analyses. 
The scope of this application of the destination choice model is regional and we were unable to obtain micro-level data for the entire study area on pedestrian barriers like number of lanes, traffic speeds and volumes, and information on intersections like treatments and crossing conditions. These are all identified as important factors for pedestrian suitability analysis (Dowling et al., 2008; Lagerwey, Hintze, Elliott, Toole \& Schneider, 2015). This limitation may be addressed in the future as this type of information becomes available.

In model development, we chose a relatively basic MNL structure and used a simple random sample of 10 zones for our choice set. Scholars have raised issues associated with model performance due to choice set generation methods, the number of alternatives to sample, and model structure (Bhat et al., 1998; Nerella \& Bhat, 2004; Pagliara \& Timmermans, 2009). Future estimations can incorporate more sophisticated sampling approaches, such as increasing the number of sampled zonal alternatives and implementing a probability feedback loop into the sampling method (e.g., strategic importance sampling (Lemp \& Kockelman, 2012)).

There may also be room to incorporate agglomeration and competition effects into the modeling effort. Destinations located in close proximity to other complementary types of destinations (e.g., in a shopping district) may yield trip-chaining efficiencies that increase their attractiveness. On the other hand, a concentration of similar destinations (e.g., multiple food outlets) might provide option value or may dilute market shares (Bernardin et al., 2009).

\subsection{CONCLUSION}

This modeling effort has advanced the understanding of pedestrian destination choice and tested its association with a variety of built environment and travel characteristics. This is a reasonable first step, given the dearth of research on this topic. The increasing availability of spatially disaggregate travel behavior and built environment data have created opportunities to improve the representation of non-motorized modes in our predictive planning tools. More fundamental study of the travel behavior of pedestrians and their decision process is needed to inform the development of these types of tools, as many questions remain about the motivations and influences of pedestrian behaviors.

Our research opens the door to many potential extensions and planning applications. Since we have developed models to predict pedestrian trip generation (Clifton et al., 2013) and now destination choices, the next logical step is to extend this effort into predicting potential routes or paths. The PAZ spatial unit is used in both stages and may accelerate a route-level analysis. Raster paths could be analyzed to highlight potential routes traversed between modeled origins and destinations in order to estimate an overall view of pedestrian activity. The most direct planning application for our pedestrian destination choice models is through the modification of regional travel demand forecasting tools to better represent walking activity. These products could also function as a standalone pedestrian planning tool, separate from a parent travel demand model. Such tools have a wide range of applications, not limited to simply identifying locations with high pedestrian activity or prioritizing investments in pedestrian infrastructure based on their potential to increase walking levels. For instance, improved models of walking demand can also be used to target areas for further data collection, generate more accurate risk exposure estimates for transportation safety analyses, or as inputs to health impact assessment 
tools. Overall, our pedestrian destination choice models set the stage for future research and the development of pedestrian-oriented planning tools with a wide range of useful applications. 


\subsection{REFERENCES}

Ben-Akiva, M., \& Lerman, S. R. (1985). Discrete choice analysis: Theory and application to travel demand. Cambridge, MA: MIT Press.

Bernardin, V. L., Koppelman, F., \& Boyce, D. (2009). Enhanced destination choice models incorporating agglomeration related to trip chaining while controlling for spatial competition. Transportation Research Record: Journal of the Transportation Research Board, 2132, 143151. http://dx.doi.org/10.3141/2132-16

Bhat, C., Govindarajan, A., \& Pulugurta, V. (1998). Disaggregate attraction-end choice modeling: Formulation and empirical analysis. Transportation Research Record: Journal of the Transportation Research Board, 1645, 60-68. http://dx.doi.org/10.3141/1645-08

Bierlaire, M. (2003). BIOGEME: A free package for the estimation of discrete choice models, Proceedings of the 3rd Swiss Transportation Research Conference, Ascona, CH. Retrieved from http://biogeme.epfl.ch/

Borgers, A., \& Timmermans, H. (1986). A model of pedestrian route choice and demand for retail facilities within inner-city shopping areas. Geographical Analysis, 18(2), 115-128. http://dx.doi.org/10.1111/j.1538-4632.1986.tb00086.x

Borgers, A. W. J., \& Timmermans, H. J. P. (1988). A context-sensitive model of spatial choice behaviour. In R. G. Golledge \& H. Timmermans (Eds.), Behavioural modelling in geography and planning (159-179). London, UK: Croom Helm.

Bureau of Labor and Statistics (BLS). (2009). Quarterly census of employment and wages. Washington, DC: US Department of Labor. Retrieved from http://www.bls.gov/cew/

Clifton, K. J., Singleton, P. A., Muhs, C. D., Schneider, R. J., \& Lagerwey, P. (2013). Improving the representation of the pedestrian environment in travel demand models - Phase I (OTRECRR-13-08). Portland, OR: Oregon Transportation Research and Education Consortium. Retrieved from http://trec.pdx.edu/research/project/510

Daly, A. (1982). Estimating choice models containing attraction variables. Transportation Research Part B: Methodological, 16(1), 5-15. http://dx.doi.org/10.1016/0191-2615(82)90037-6

Dowling, R., Reinke, D., Flannery, A., Ryus, P., Vandehey, M., Petritsch, T., Landis, B., Rouphail, N., \& Bonneson, J. (2008). Multimodal level of service analysis for urban streets (NCHRP Report 616). Washington, DC: Transportation Research Board. Retrieved from http://onlinepubs.trb.org/onlinepubs/nchrp/nchrp_rpt_616.pdf 
Eash, R. (1999). Destination and mode choice models for nonmotorized travel. Transportation Research Record: Journal of the Transportation Research Board, 1674, 1-8.

http://dx.doi.org/10.3141/1674-01

Ewing, R., \& Cervero, R. (2010). Travel and the built environment: A meta-analysis. Journal of the American Planning Association, 76(3), 265-294.

http://dx.doi.org/10.1080/01944361003766766

Khan, M., Kockelman, K., \& Xiong, X. (2014). Models for anticipating non-motorized travel choices, and the role of the built environment. Transport Policy, 35, 117-126.

http://dx.doi.org/10.1016/j.tranpol.2014.05.008

Koppelman, F. S., \& Bhat, C. (2006). A self-instructing course in mode choice modeling: multinomial and nested logit models. Washington, DC: U.S. Department of Transportation, Federal Transit Administration. Retrieved from http://caee.utexas.edu/prof/bhat/COURSES/LM_Draft_060131Final-060630.pdf

Lagerwey, P. A., Hintze, M. J., Elliott, J. B., Toole, J. L., \& Schneider, R. J. (2015). Pedestrian and bicycle transportation along existing roads: ActiveTrans priority tool guidebook (NCHRP Report 803). Washington, DC: Transportation Research Board. Retrieved from http://onlinepubs.trb.org/onlinepubs/nchrp/nchrp_rpt_803.pdf

Lemp, J. D., \& Kockelman, K. M. (2012). Strategic sampling for large choice sets in estimation and application. Transportation Research Part A: Policy and Practice, 46(3), 602-613. http://dx.doi.org/10.1016/j.tra.2011.11.004

Metro. (2008). Metro travel forecasting: 2008 trip-based demand model methodology report. Portland, OR: Metro. Retrieved from http://www.oregonmetro.gov/sites/default/files/transportation_model_documentation.pdf

Nerella, S., \& Bhat, C. R. (2004). Numerical analysis of effect of sampling of alternatives in discrete choice models. Transportation Research Record: Journal of the Transportation Research Board, 1894, 11-19. http://dx.doi.org/10.3141/1894-02

Oregon Modeling Steering Committee (OMSC). (2011). Oregon travel and activity survey. Salem, OR: Oregon Department of Transportation. Retrieved from http://www.oregon.gov/ODOT/TD/TP/pages/travelsurvey.aspx

Ortúzar, J. D., \& Willumsen, L. G. (2011). Modelling transport. Chichester, UK: Wiley.

Pagliara, F., \& Timmermans, H. (2009). Choice set generation in spatial contexts: A review. Transportation Letters, 1(3), 181-196. http://dx.doi.org/10.3328/tl.2009.01.03.181-196

Pas, E. I. (1985). State of the art and research opportunities in travel demand: Another perspective. Transportation Research Part A: General, 19(5), 460-64.

http://dx.doi.org/10.1016/0191-2607(85)90048-2 
Pozsgay, M. A., \& Bhat, C. R. (2001). Destination choice modeling for home-based recreational trips: Analysis and implications for land use, transportation, and air quality planning.

Transportation Research Record: Journal of the Transportation Research Board, 1777, 47-54. http://dx.doi.org/10.3141/1777-05

Rodríguez, D. A., \& Joo, J. (2004). The relationship between non-motorized mode choice and the local physical environment. Transportation Research Part D: Transport and Environment, 9(2), 151-173. http://dx.doi.org/10.1016/j.trd.2003.11.001

Saelens, B. E., \& Handy, S. L. (2008). Built environment correlates of walking: A review. Medicine and Science in Sports and Exercise, 40(7 Suppl), S550-S566.

http://dx.doi.org/10.1249/MSS.0b013e31817c67a4

Saelens, B. E., Sallis, J. F., \& Frank, L. D. (2003). Environmental correlates of walking and cycling: Findings from the transportation, urban design, and planning literatures. Annals of Behavioral Medicine, 25(2), 80-91. http://dx.doi.org/10.1207/S15324796ABM2502_03

Schneider, R. J., Arnold, L. S., \& Ragland, D. R. (2009). Pilot model for estimating pedestrian intersection crossing volumes. Transportation Research Record: Journal of the Transportation Research Board, 2140, 13-26. http://dx.doi.org/10.3141/2140-02

Singleton, P. A., \& Clifton, K. J. (2013). Pedestrians in regional travel demand forecasting models: State-of-the-practice. Presented at the $92^{\text {nd }}$ Annual Meeting of the Transportation Research Board, Washington, DC. Retrieved from http://trid.trb.org/view/2013/C/1242847

Singleton, P. A., Schneider, R. J., Muhs, C. D., \& Clifton, K. J. (2014). The Pedestrian Index of the Environment (PIE): Representing the walking environment in planning applications. Presented at the $93^{\text {rd }}$ Annual Meeting of the Transportation Research Board, Washington, DC. Retrieved from http://trid.trb.org/view/2014/C/1289281 
Transportation Research and Education Center

Portland State University

1900 S.W. Fourth Ave., Suite 175

Portland, OR 97201 